\title{
Real-time reporting of baleen whale passive acoustic detections from ocean gliders
}

\author{
Mark F. Baumgartner ${ }^{\text {a) }}$ \\ Biology Department, Woods Hole Oceanographic Institution, 266 Woods Hole Road, MS \#33, Woods Hole, \\ Massachusetts 02543 \\ David M. Fratantoni \\ Physical Oceanography Department, Woods Hole Oceanographic Institution, 266 Woods Hole Road, MS \#30, \\ Woods Hole, Massachusetts 02543 \\ Thomas P. Hurst \\ Applied Ocean Physics and Engineering Department, Woods Hole Oceanographic Institution, \\ 266 Woods Hole Road, MS \#18, Woods Hole, Massachusetts 02543 \\ Moira W. Brown \\ John H. Prescott Marine Laboratory, New England Aquarium, Central Wharf, Boston, Massachusetts 02110
}

Tim V. N. Cole and Sofie M. Van Parijs

Northeast Fisheries Science Center, 166 Water Street, Woods Hole, Massachusetts 02543

Mark Johnson ${ }^{\text {b) }}$

Scottish Oceans Institute, East Sands, University of St. Andrews, St. Andrews, Fife, KY16 8LB, United Kingdom

(Received 29 March 2013; revised 2 June 2013; accepted 26 June 2013)

\begin{abstract}
In the past decade, much progress has been made in real-time passive acoustic monitoring of marine mammal occurrence and distribution from autonomous platforms (e.g., gliders, floats, buoys), but current systems focus primarily on a single call type produced by a single species, often from a single location. A hardware and software system was developed to detect, classify, and report 14 call types produced by 4 species of baleen whales in real time from ocean gliders. During a 3-week deployment in the central Gulf of Maine in late November and early December 2012, two gliders reported over 25000 acoustic detections attributed to fin, humpback, sei, and right whales. The overall false detection rate for individual calls was $14 \%$, and for right, humpback, and fin whales, false predictions of occurrence during 15-min reporting periods were 5\% or less. Transmitted pitch tracks-compact representations of sounds-allowed unambiguous identification of both humpback and fin whale song. Of the ten cases when whales were sighted during aerial or shipboard surveys and a glider was within $20 \mathrm{~km}$ of the sighting location, nine were accompanied by real-time acoustic detections of the same species by the glider within $\pm 12 \mathrm{~h}$ of the sighting time.
\end{abstract}

(C) 2013 Acoustical Society of America. [http://dx.doi.org/10.1121/1.4816406]

PACS number(s): 43.30.Sf [WWA]

Pages: $1814-1823$

\section{INTRODUCTION}

Monitoring the occurrence and distribution of any species in real time is challenging but doing so for marine mammals is particularly difficult because of their often-cryptic behavior and the inaccessibility of their habitat. Traditional visual survey methods involving aircraft or ships are expensive and can be ineffective at detecting small aggregations of animals that spend significant periods of time submerged and out of view at the sea surface. Visual methods are also naturally limited by factors that affect visibility, such as rough seas, fog, rain, snow, and darkness. In contrast, passive acoustic monitoring techniques offer the possibility to

\footnotetext{
${ }^{\text {a) }}$ Author to whom correspondence should be addressed. Electronic mail: mbaumgartner@whoi.edu

b) Also at Department of Bioscience, University of Aarhus, C.F.Møllers Allé 3, 8000 Aarhus C, Denmark.
}

continuously detect vocalizing animals at much greater ranges and for much longer periods of time (weeks to years; Mellinger et al., 2007; Van Parijs et al., 2009). While detectability is limited to individuals that vocalize, Clark et al. (2010) found that passive acoustic monitoring was more reliable at detecting occurrence than aerial surveys for a facultative vocalizer, the North Atlantic right whale (Eubalaena glacialis). The vast majority of passive acoustic monitoring applications today utilize moored acoustic recorders for which the archived audio is not accessible until after recovery (typically months after deployment) and species-specific call detections are unavailable until after analysis (typically months to years after recovery). Passive acoustic recording has also been conducted from autonomous mobile platforms (e.g., ocean gliders, profiling floats; Moore et al., 2007; Baumgartner and Fratantoni, 2008), but detection data are similarly unavailable until the platform is recovered and the audio is analyzed. Recent advances in low-power digital 
signal processors (DSPs), detection algorithms, and satellite communications have made real-time audio processing, sound detection, classification, and reporting from autonomous platforms feasible in the past decade.

Real-time detection and remote reporting of marine mammal sounds can be useful for both management and scientific applications. Minimizing risks posed to marine mammals by human activities in the ocean, such as shipping, fishing, oil and gas extraction, offshore construction, and military activities, currently rely on (1) published information about seasonal distribution (e.g., MacLeod et al., 2006), (2) large-scale habitat models (e.g., Forney et al., 2012), (3) passive acoustic recording (e.g., Kumar et al., 2012), (4) visual monitoring via ships or aircraft (e.g., Cole et al., 2007), (5) real-time passive acoustic monitoring by an analyst (e.g., Gillespie et al., 2008), or (6) automated real-time passive acoustic detections from moored buoys (e.g., Clark et al., 2005). Of the real-time monitoring approaches (4-6), automated real-time passive acoustic detection is comparatively less expensive, less labor intensive, and more persistent than those relying on visual or aural observations collected by humans. While visual surveys can provide critical data that cannot be collected acoustically (e.g., photographs for individual identification, health assessment, or scarring and injury studies) and boat-based surveys in particular can collect vital biological information (e.g., biopsy and fecal samples), passive acoustics may be the best available technique for assessing the occurrence of species that produce wellknown calls (Clark et al., 2010). Thus, real-time passive acoustic detection from autonomous platforms has the potential to greatly expand the spatiotemporal scales and resolutions at which monitoring is currently conducted, and to do so cost-effectively (Van Parijs et al., 2009).

For scientific applications, real-time detection can be used for two purposes: (1) Aiding in locating animals for study, and (2) allowing adaptive surveys from mobile autonomous platforms. Studies that rely on marine mammal visual observations (e.g., photo-identification, focal follows, health assessment) or actual contact with animals (e.g., biopsy sampling, tag deployment) can be crippled by poor weather and a lack of subject animals. In our own experience, more time is often spent searching for animals than actually studying them, particularly for rare or cryptic species. Real-time detection and reporting from autonomous platforms can support such studies by providing persistent reconnaissance for subject animals, thus improving the efficiency of at-sea research efforts. Autonomous mobile platforms can also adapt to local conditions by altering their survey mission based on an assessment of real-time detections by shore-side researchers. By holding station to extend monitoring in a particular location where detections are abundant, the confidence in those detections can be improved and additional data (e.g., oceanographic observations) can be collected by the platform. Likewise, if the occurrence of a target species is not detected in a particular location, the survey can be moved to a nearby area.

Tremendous progress has been made in recent years to develop embedded systems to detect and report marine mammal sounds from autonomous platforms (Clark et al.,
2005; Simard et al., 2006; Spaulding et al., 2009; Van Parijs et al., 2009; Klinck et al., 2012; Matsumoto et al., 2013). However, most systems currently focus on a single call type produced by a single species, often in a single location. Automated detection and reporting from mobile autonomous platforms show great promise for assessing the spatial distribution of vocalizing animals (Klinck et al., 2012; Matsumoto et al., 2013), but these systems need to be expanded to simultaneously detect the calls of a wide variety of species. We report here on a new autonomous detection and classification system deployed on ocean gliders that can detect 14 call types produced by four species of baleen whales: Fin (Balaenoptera physalus), humpback, (Megaptera novaeangliae), sei (Balaenoptera borealis), and North Atlantic right whales. We deployed the system for 3 weeks in the central Gulf of Maine during late November and early December and assessed its performance by (1) comparing reported real-time detections to audio recorded by the system, and (2) comparing the locations of real-time detections to sighting locations from concurrent aerial and shipboard surveys.

\section{SYSTEM}

Audio was processed in real-time with the programmable digital acoustic monitoring (DMON) instrument, which consisted of a single hydrophone (WHOI custom built, end-capped cylinders with Navy type II ceramics), a low-power and low-noise preamplifier (20 dB gain), a user programmable gain stage (4.6/13.2 dB), a 6-pole Sallen-Key anti-alias filter, a 16-bit successive-approximation analog-todigital converter, a Texas Instruments TMS320C5509A DSP, 32 GB of FLASH memory, and serial (RS232/485) input/output lines. Configured for this study, the DMON had an $8-7500 \mathrm{~Hz}$ bandwidth, $36 \mathrm{~dB}$ re $\mu \mathrm{Pa} /{ }_{\sqrt{ }} \mathrm{Hz}$ noise floor at $2 \mathrm{kHz}$, and $-169 \mathrm{~dB}$ re $\mathrm{V} / \mu \mathrm{Pa}$ sensitivity at $2 \mathrm{kHz}$. The hydrophone was potted in a faired acoustically transparent medium (Conathane TU-401 urethane, Cytec Industries, Inc.) and mounted to the underside of a Slocum electric glider (Teledyne Webb Research); because of this faired design and the slow movement of the glider, flow noise was negligible. This same external hydrophone housing featured a watertight universal serial bus (USB) connector that allowed a user to communicate with the DMON via a personal computer after the glider was sealed for deployment. The DMON electronics were housed inside the glider scientific bay where (1) serial connections allowed the DMON and glider science computer to communicate, and (2) power from the glider battery pack was supplied to trickle charge the DMON's integrated $5 \mathrm{~A}-\mathrm{hr}$ lithium polymer rechargeable cell. To minimize power consumption, the DMON DSP does not have a floating-point unit, so all calculations involving real numbers were done with fixed-point integer (16- or 32-bit) arithmetic using dynamic scaling where appropriate. When running the detection and classification software described below, the instrument consumed $130 \mathrm{~mW}$ of power.

The low-frequency detection and classification system (LFDCS) of Baumgartner and Mussoline (2011) was ported to and optimized for operation on the DMON; the algorithm is 
only briefly described here (section references in the following are from Baumgartner and Mussoline, 2011). The high-level LFDCS software made use of a real-time audio processing application programming interface (API) implemented on the DMON to handle basic operating system functions, such as job scheduling, memory access, audio buffering, and serial communications. Real-time 16-bit audio was low-pass filtered and decimated from the native $60-\mathrm{kHz}$ sampling rate to $2000 \mathrm{~Hz}$ and recorded continuously in FLASH memory using lossless compression (Johnson et al., 2013). Spectrograms were constructed using a fast Fourier transform of the $2000 \mathrm{~Hz}$ audio assembled into 512 sample frames with a Hann window and a frame-to-frame overlap of 384 samples (75\%), yielding a spectrogram time step of $64 \mathrm{~ms}$ and frequency resolution of $3.9 \mathrm{~Hz}$. Spectrograms were then smoothed using a $3 \times 3$ smoothing kernel and equalized by subtracting an exponentially weighted running mean from each frequency band (Secs. II A and II B of Baumgartner and Mussoline, 2011). Individual spectra with many high amplitude elements $(>50$ elements with amplitudes $>9.5 \mathrm{~dB}$ above background) or a high average amplitude ( $>5 \mathrm{~dB}$ above background) were blanked to reduce the effects of broadband noise (modified implementation of Sec. II C). The LFDCS uses a contour following algorithm to track the fundamental frequency of sounds in the equalized spectrograms; these contours are called pitch tracks (Sec. II D).

To classify calls, seven amplitude-weighted attributes were extracted from each pitch track: duration, average frequency, frequency variation, overall time-frequency slope, and the time-frequency slope for each third of the pitch track (beginning, middle, end) (Sec. II E; note that addition of separate slopes for each third of the pitch track was not included in Baumgartner and Mussoline, 2011). A quadratic discriminant function analysis using these attributes and a library of known call types was then performed to classify each pitch track (Sec. II F). The "quality" of the classification was judged using the Mahalanobis distance (MD), a statistic that measures the multivariate distance from the call attribute vector to the mean attribute vector of the classified call type. For calls that match a call type very well, the MD will be small; a threshold of $\mathrm{MD}<3$ was used here. If the seven attributes of a call type are multivariate normal, then $\mathrm{MD}<3$ encompasses $75 \%$ of the multivariate probability distribution (for a multivariate normal distribution, the square of MD has a chisquared distribution with $p$ degrees of freedom where $p$ is the number of attributes in the call library; $p=7$ here). This threshold ensured that "high quality" calls (i.e., those with attributes closer to the multivariate mean) were retained, while "low quality" yet still genuine calls were discarded. We used a call library containing 14 call types produced by four species of baleen whales: fin whale $20-\mathrm{Hz}$ pulses (Watkins et al., 1987), sei whale low-frequency downsweeps (Rankin and Barlow, 2007; Baumgartner et al., 2008), right whale upcalls (Schevill et al., 1962; Clark, 1982, 1983), and six distinct humpback whale calls. Variants of right whale upcalls and sei whale downsweeps were represented by four and three call types, respectively. The call library, which consists simply of the mean attribute vector and the inverse and determinant of the attribute variance-covariance matrix for each call type, was constructed from exemplars extracted from a variety of acoustic recordings collected in the northwest Atlantic Ocean (Baumgartner and Mussoline, 2011).

For each detection event, the DMON/LFDCS produced a pitch track (i.e., a time series of frequency and amplitude pairs), average call amplitude, classified call type, and MD. For calls with average amplitudes greater than $11 \mathrm{~dB}$ above background, these data were written to FLASH memory as a text string based on the National Marine Electronics Association (NMEA) standard. Each hour, a maximum of 8 $\mathrm{kB}$ of these detection strings were sent to the glider science computer for relay to shore, resulting in the transmission of only a subset of detailed detection information. All calls with average amplitudes greater than $11 \mathrm{~dB}$ above background and $\mathrm{MD}<3$ were tallied in 14 separate bins corresponding to the 14 call types in the call library. Every $15 \mathrm{~min}$, the DMON sent an NMEA-like string with these tallies to the glider science computer and wrote this same string to FLASH memory; these 15 -min periods will be referred to below as tally periods. Finally, the DMON also generated status strings every $20 \mathrm{~min}$ that contained information on the state of the LFDCS processing as well as hardware status (e.g., DMON battery voltage); these strings were sent to the glider computer and written to the DMON's FLASH memory. The glider science computer assembled all of these received strings and transmitted them as well as other sensor (e.g., temperature, salinity, chlorophyll fluorescence) and vehicle status data to a shore-side computer via the glider's Iridium satellite modem. For our study, the glider surfaced approximately once every $2 \mathrm{~h}$ to transmit these data. The detection data were immediately displayed on a publicly accessible web server in tabular and graphical formats. Surface waves, internal pumps, and radio transmitters produce an inordinate amount of noise when the gliders surface for these communication sessions or to obtain a position via the global positioning system (GPS). The glider science computer was programmed to signal the DMON using unique NMEA-like strings upon surfacing and again upon diving once surface activities were completed. The DMON used these strings to halt the detection process so that no false detections were produced during the noisy surfacing period, although audio recording continued uninterrupted.

Two gliders were deployed in the Outer Fall region of the central Gulf of Maine [Fig. 1(a)] on 12 November 2012 from the R/V Gulf Challenger. The gliders remained at sea for 3 weeks and were recovered by the R/V Endeavor on 4 December. The primary mission of the gliders was to characterize the distribution of four baleen whale species in both space and time for 2 weeks in advance of a cruise to the region aboard the R/V Endeavor to study local oceanographic conditions and the whales' prey. As expected for the time of year, periods of low winds and calm seas were infrequent and short [Fig. 1(b)], making traditional shipboard marine mammal observations difficult. The real time detection data from the gliders were intended to aid in our finding whales quickly once on location aboard the R/V Endeavor. Glider we10 was tasked with completing a spatial survey of the study area, while glider we 08 remained at a single station for the duration of its mission to characterize temporal variability in whale calling behavior. 

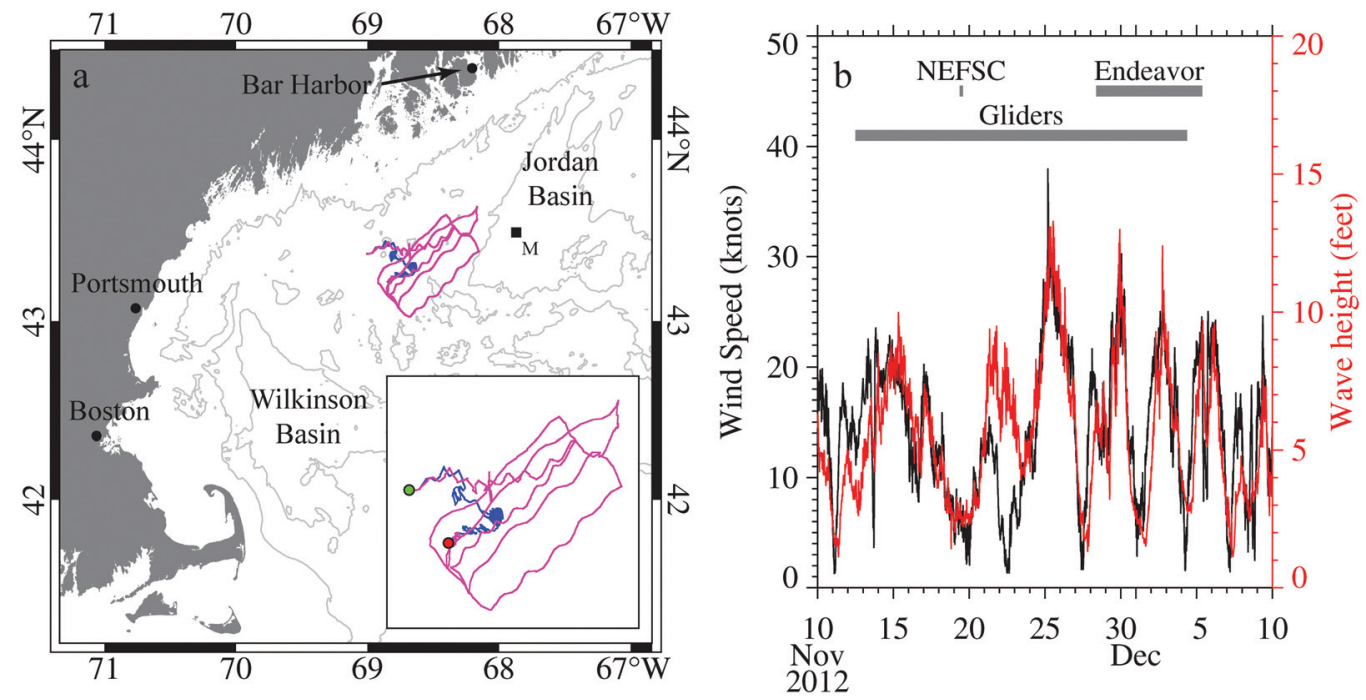

FIG. 1. (a) Tracks of gliders we08 (blue) and we10 (magenta) in the Outer Fall region of the central Gulf of Maine. Northeast Regional Association of Coastal and Ocean Observing Systems (NERACOOS) buoy M shown as a filled black square. Inset shows deployment (filled green circle) and recovery (filled red circle) locations. (b) Wind speed (black) and wave height (red) at NERACOOS buoy M during the study period. Gray bars indicate times of glider deployments, R/V Endeavor cruise, and Northeast Fisheries Science Center (NEFSC) aerial survey.

\section{RESULTS AND EVALUATION}

The two gliders spent a combined total of 43.7 days at sea and the DMON/LFDCS was actively detecting and classifying sounds $84 \%$ of that time; long periods of noise during surfacings accounted for the remaining $16 \%$ of the time when the LFDCS was idle. A total of 478621 sounds with amplitudes greater than $11 \mathrm{~dB}$ above background were detected and pitch tracked by the two gliders, and 117524 $(25 \%)$ of the pitch tracks were transmitted to shore in real time via satellite. Transmission problems owing to dropped Iridium satellite connections prevented a fraction of the DMON/LFDCS data from being received successfully on shore: $5 \%$ of pitch tracks and $12 \%$ of tally strings were unsuccessfully transmitted. Between $16 \%$ and $25 \%$ of all pitch tracks classified as fin, right, humpback, and sei whales were transmitted successfully to shore in real time (Table I).

\section{A. Detector performance}

After recovery of the gliders on 4 December, we were able to access the continuous audio recorded by the DMON and compare it to the real time detection data to verify that both the pitch tracking algorithm and the classification procedure were working as expected. The pitch tracks that were transmitted to shore by the gliders faithfully represented the calls of right, humpback, and fin whales present in the archived audio recordings (Fig. 2). Although the gliders sent back only a subset of the pitch tracks generated by the DMON/LFDCS (up to a maximum of $8 \mathrm{kB}$ of pitch tracks per hour), those data were extremely helpful in evaluating individual call classifications in real time. For example, fin whale $20-\mathrm{Hz}$ calls are produced in very regular patterns (e.g., Watkins et al., 1987; Clark et al., 2002; Morano et al., 2012), and these patterns or songs were easily identified in the pitch track data [note the regularity of fin whale $20-\mathrm{Hz}$ call detections in Fig. 2(a)]. Although the fin whale $20-\mathrm{Hz}$ call classifications appear to be quite accurate (see below), in situations where confidence in individual call classifications may be modest, the appearance of patterned calling in the pitch tracks allows an analyst to say with near certainty that one or more fin whales is present. Similarly, humpback whale song is unmistakable in the pitch tracks [Fig. 2(a)]. None of the song notes shown in Fig. 2(a) were in our call library, so the DMON/LFDCS was not tallying these calls; however, by recognizing the characteristic pattern in the real-time pitch-track data, an analyst can again say with near certainty that one or

TABLE I. Audio confirmation of detections (MD $<3$ ) transmitted in real time as pitch tracks or included in 15 -min tallies. The significance $(p$-value) of the logistic regression relating the analyst-determined occurrence of vocalizing whales to the number of detected calls during 15 -min tally periods for both gliders is shown. False and missed occurrence rates were calculated using $N_{\min }$. All 6233 transmitted pitch tracks were reviewed for the individual call analysis, while analysis of 15-min tallies included only data for the $24 \mathrm{~h}$ period starting on 1 December 2012 06:00 GMT.

\begin{tabular}{|c|c|c|c|c|c|c|c|c|}
\hline \multirow[b]{2}{*}{ Species } & \multicolumn{4}{|c|}{ Individual calls } & \multicolumn{4}{|c|}{ 15-min tallies } \\
\hline & $\begin{array}{c}\text { Total } \\
\text { detections }\end{array}$ & $\begin{array}{l}\text { Transmitted } \\
\text { pitch tracks }\end{array}$ & $\begin{array}{c}\text { False } \\
\text { detections }\end{array}$ & $\begin{array}{l}\text { False detection } \\
\text { rate }(\%)\end{array}$ & $\begin{array}{c}\text { Logistic regression } \\
p \text {-value }\end{array}$ & $\mathrm{N}_{\min }$ & $\begin{array}{l}\text { False occurrence } \\
\quad \text { rate }(\%)\end{array}$ & $\begin{array}{c}\text { Missed occurrence } \\
\text { rate }(\%)\end{array}$ \\
\hline Fin & 20912 & 5328 & 503 & 9.4 & $<0.0001$ & 8 & 0.0 & 48.1 \\
\hline Right & 1621 & 348 & 52 & 14.9 & $<0.0001$ & 2 & 2.9 & 48.5 \\
\hline Humpback & 2915 & 462 & 212 & 45.9 & 0.0053 & 4 & 5.0 & 80.7 \\
\hline Sei & 579 & 95 & 95 & 100.0 & - & - & - & - \\
\hline Total & 26027 & 6233 & 862 & 13.8 & & & & \\
\hline
\end{tabular}




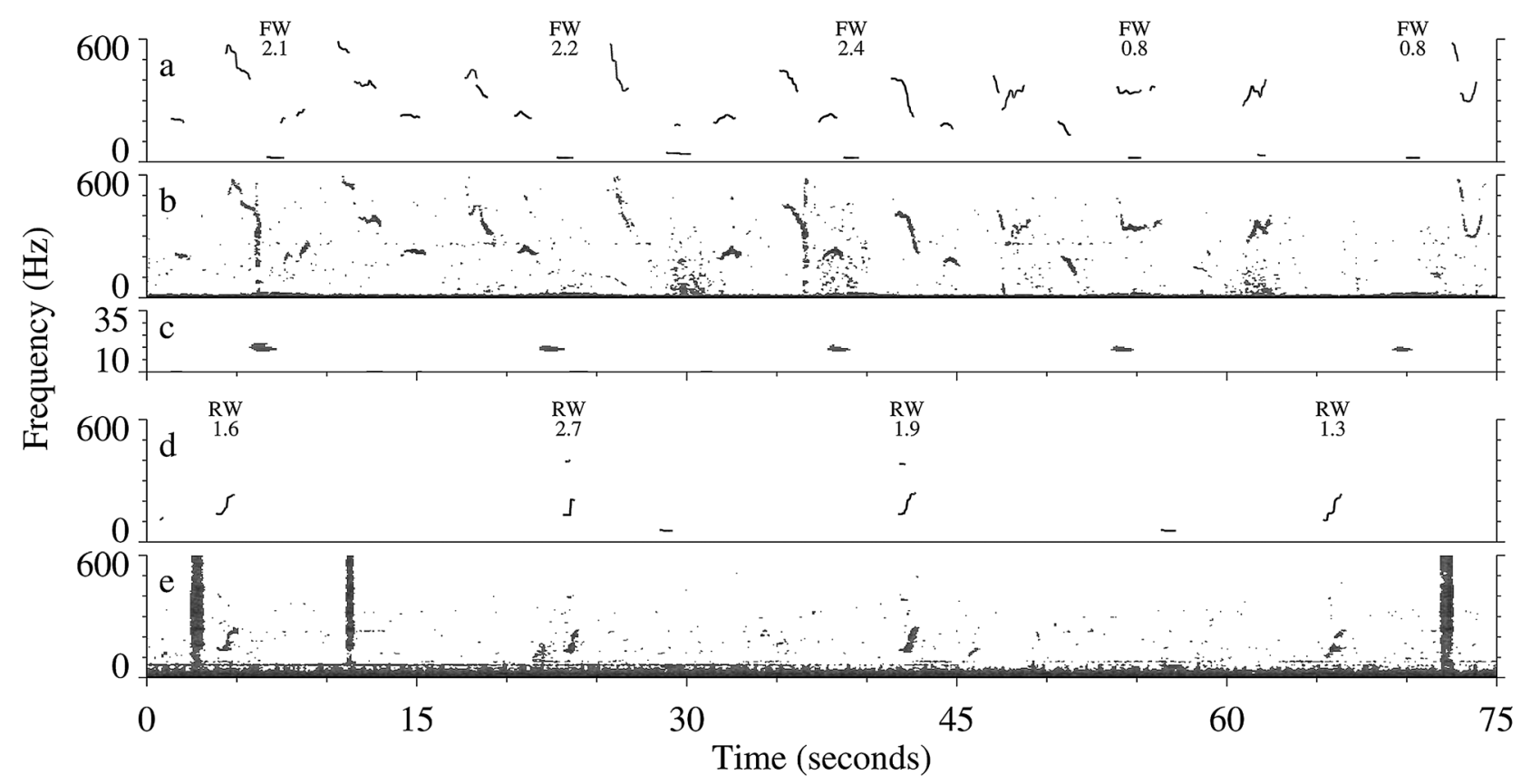

FIG. 2. (a) Pitch tracks and associated classification information received in real time from glider we08 starting on 2 December 2012 at 19:30:48 GMT. Pitch tracks are colored according to amplitude relative to background; dark gray colors are high amplitude, light gray colors are low amplitude. For calls with Mahalanobis distances (MD) less than 3, the classified species is shown above the plot, and MD is shown just below the species abbreviation. Species are indicated as "FW" for fin whale, and "RW" for right whale. (b and c) Spectrogram of archived audio corresponding to the same time period as that shown in (a). Audio was only accessible after recovery of the glider. Spectrogram parameters were as follows: (b) sampling rate $=2000 \mathrm{~Hz}$, frame size $=512$, Hann window, overlap $=75 \%$, time step $=64 \mathrm{~ms}$, frequency resolution $=3.9 \mathrm{~Hz} ;$ (c) sampling rate $=2000 \mathrm{~Hz}$, frame size $=4096$, Hann window, overlap $=87.5 \%$, time step $=256 \mathrm{~ms}$, frequency resolution $=0.49 \mathrm{~Hz}$. (d) Pitch tracks and associated classification information received in real time from glider we 10 starting on 17 November 2012 at 20:44:35 GMT. (e) Spectrogram of archived audio corresponding to the same time period as that shown in (d). Broadband sounds in (e) were produced by the glider.

more humpback whales is present. This is particularly important when evaluating right whale detections, as humpbacks are well known for making similar upsweeps to those of right whales and distinguishing between the two species is often difficult for both automated detectors and analysts. The realtime pitch-track data can be used to glean the context of right whale detections, such that if humpback whale calls are absent in the pitch tracks, then confidence in the classification of right whale upsweeps can be increased [e.g., Fig. 2(d)].

A total of 26027 detections with MD $<3$ were tallied and reported by both gliders combined, and pitch tracks for $6233(24 \%)$ of these detections were transmitted to shore (Table I). An experienced analyst (MFB) reviewed the archived audio associated with each of the transmitted pitch tracks both aurally and visually in a spectrogram (frame size - 512; Hann window; overlap-75\%; time step-64 ms; frequency resolution- $-3.9 \mathrm{~Hz}$ ) to confirm the species (Table I). The overall false detection rate (i.e., the percentage of transmitted pitch tracks that were incorrectly detected or classified) for all species combined was $14 \%$, and for fin, right, and humpback whales, false detection rates were $9 \%, 15 \%$, and $46 \%$, respectively. The sei whale false detection rate was $100 \%$ (Table I); however, the total number of calls attributed to sei whales was low: 579 detections were classified as sei whale calls for both gliders combined, corresponding to an average rate of just 13.2 calls per glider per day. False detections were caused primarily by ambient (e.g., ships, breaking waves) and platform noise, and secondarily by the calls of other whales. In the case of humpback whales, $9.7 \%$ of false detections were incorrectly classified right whale upcalls. All of the sei whale calls examined were clearly false detections; none resembled the stereotypical 80 - to $35-\mathrm{Hz}$ 1.4-s downsweep described for the Gulf of Maine and none occurred in pairs or triplets, a characteristic that is likely diagnostic of the species (Baumgartner et al., 2008). Fin whale false detections occurred more frequently than expected when the glider was in the upper $20 \mathrm{~m}$ (Pearson's $\chi^{2}$ test of the depth of false detections binned in $20 \mathrm{~m}$ intervals from the surface to $200 \mathrm{~m} ; \chi^{2}=67.5, \mathrm{df}=9, p$ $<0.0001$ ), suggesting that low-frequency wave noise is one of the causes of false detections for fin whale $20-\mathrm{Hz}$ calls.

In addition to assessing the accuracy of individual calls, we also manually identified all calls received on both gliders during a 24-h period to determine the minimum number of detected calls required to accurately predict the presence of vocalizing whales in a 15 -min period (the period over which the DMON/LFDCS reported call tallies). Calls were manually identified on gliders we 08 and we 10 during the $24 \mathrm{~h}$ period starting on 1 December 2012 06:00 GMT by reviewing 1-min long spectrograms (parameters as above) and the associated audio. Subsequently, the occurrence (presence/absence) of calls from fin, right, humpback, and sei whales identified by the analyst was noted for each 15 -min tally period reported by the gliders. For each species, logistic regression was used to relate the analyst-identified occurrence of vocally active whales to the number of species-specific calls reported during each tally period for each glider $(n=60$ periods for glider we $08, n=74$ periods for glider we10; periods when the gliders were at the surface acquiring a GPS position or transmitting data via Iridium were excluded). The 
relative probability of occurrence of vocally active whales was strongly related to the total number of detected calls for fin $(p<0.0001)$, right $(p<0.0001)$, and humpback whales $(p=0.0053)$. Logistic regression could not be used to assess sei whale detections, because the analyst identified no sei whale low-frequency downsweeps on either glider recording during the 24-h analysis period.

Using the logistic regression equations, the minimum number of detected calls required to achieve a $95 \%$ or better probability of accurately predicting the occurrence of vocally active whales $\left(N_{\min }\right)$ was estimated as

$$
N_{\min }=\left\lceil\frac{1}{\beta_{1}}\left[\ln \left(\frac{\theta}{1-\theta}\right)-\beta_{0}\right]\right\rceil,
$$

where $\theta=0.95, \beta_{0}$ and $\beta_{1}$ are the logistic regression coefficients (intercept and slope, respectively), and the notation \lceil\rceil indicates rounding up. Occurrence of a species was predicted simply when the number of DMON/LFDCS detections for that species $(N)$ in a tally period was equal to or greater than $N_{\text {min }}$. Occurrence was falsely predicted in $5 \%$ or less of the tally periods where species-specific calls were absent for fin $\left(N_{\min }=8\right)$, right $\left(N_{\min }=2\right)$, and humpback $\left(N_{\min }=4\right)$ whales, while occurrence was not predicted for nearly half of the tally periods where fin and right whale calls were actually present, and $81 \%$ of the tally periods where humpback whale calls were present (Table I). Although $N_{\text {min }}$ could not be estimated for sei whales, if specified as $N_{\text {min }}=1,2$, or 3 , the occurrence of sei whales would have been falsely predicted in $18 \%, 4 \%$, or $2 \%$ of the tally periods where sei whale calls were absent, respectively.

Because the same data were used to both estimate $N_{\text {min }}$ and determine false and missed occurrence rates, the performance statistics for the 15-min tally periods in Table I are probably optimistic. To estimate more realistic false and missed occurrence rates, a new set of logistic regressions was fit to the glider we08 data only, and performance statistics were generated with the independent glider we10 data. The resulting logistic regressions were still significant, but the minimum number of detections was slightly different for fin ( $p$ $\left.<0.0001, N_{\min }=9\right)$, right $\left(p<0.0001, N_{\min }=1\right)$, and humpback $\left(p=0.0172, N_{\min }=2\right)$ whales. Occurrence was falsely predicted in 0 and $4 \%$ of the glider we10 tally periods where fin and right whale calls were absent, respectively, while occurrence was not predicted for $27 \%$ and $26 \%$ of the tally periods where fin and right whale calls were actually present. The rate of humpback whale false $(23 \%)$ and missed $(62 \%)$ occurrence was considerably higher than that of fin and right whales. Fin, right, and humpback whale presence was correctly predicted in 11 of 11 (100\%), 38 of 39 (97.4\%), and 23 of $26(88.5 \%)$ tally periods where $N \geq N_{\min }$, respectively, suggesting that the $N_{\text {min }}$ estimates derived from the glider we08 data were accurate (i.e., probability of accurate prediction was $\geq 95 \%$ ) when applied to the glider we10 data for fin and right whales, and nearly so for humpback whales.

\section{B. Visual confirmation}

On 19 November 2012, the National Oceanic and Atmospheric Administration (NOAA) Northeast Fisheries
Science Center (NEFSC) conducted an aerial survey of the study area in a Twin Otter aircraft flown at $185 \mathrm{~km} \mathrm{~h}^{-1}$ and an altitude of $230 \mathrm{~m}$. Two observers, one on each side of the plane, scanned the sea surface from ahead to abeam of the plane's line of flight through bubble windows that had clear views from immediately below the plane out to the horizon. The survey's effective strip half-width-the distance within which the probability that a whale at the surface will be detected is $1-$ was $2.04 \mathrm{~km}$ in Beaufort sea states of 4 or less (NEFSC, unpublished data). A total of $710 \mathrm{~km}$ of trackline was flown in the study area [Fig. 3(a)] during excellent sighting conditions: visibility was unlimited and sea state was between Beaufort 2 and 3. The observers recorded three sightings of fin whales (each consisting of a single animal), two sightings of single unidentified rorquals, and a sighting of two unidentified large whales (noted at the time as "possibly right whales"). No confirmed sightings of right, humpback, or sei whales were recorded. For one of the fin whale sightings, glider we 08 reported 15 tally periods with $N \geq 8$ for fin whale $20-\mathrm{Hz}$ calls while within $\pm 12 \mathrm{~h}$ of the sighting time and $20 \mathrm{~km}$ of the sighting location (recall $N_{\text {min }}=8$ for fin whales; Table I). This was the only case where a glider came within $20 \mathrm{~km}$ of a sighting. During the week of the survey ( \pm 3.5 days), both gliders predicted the occurrence of [Fig. 3(b)] and correctly detected [Fig. 3(c)] right, humpback, and fin whales.

From 29 November to 4 December 2012, sighting surveys were conducted in the study area from the $56 \mathrm{~m} \mathrm{R} / \mathrm{V}$ Endeavor. Three observers stationed on an expansive flying bridge $8.5 \mathrm{~m}$ above the sea surface searched from -90 to $+90^{\circ}$ of the bow using $7 \times 50$ hand-held binoculars and the naked eye while the ship steamed at 6-11 kn. Search effort was conducted continuously during daylight hours, although sighting conditions were often quite poor with seas regularly $8-10 \mathrm{ft}$ and winds $20-25 \mathrm{kn}$ [Fig. 1(b)]. A total of $311 \mathrm{~km}$ of trackline were completed in sea states of Beaufort 5 or less during which as many as nine right whales (five sightings of single animals, two sightings of pairs), seven fin whales (five sightings of single animals, one sighting of a pair), four humpback whales (four sightings of single animals), and one sei whale were encountered [Fig. 4(a)]. We took care to avoid recording multiple sightings of the same whale during a single sighting event, but with the exception of four photoidentified right whales, it is possible that the number of individual animals encountered was lower than that reported here owing to our recording a sighting of the same whale during multiple encounters. One or both of the gliders came within $20 \mathrm{~km}$ of nine sighting locations during the $12 \mathrm{~h}$ before or after the sighting times [Figs. 4(b) and 4(c)]. This resulted in ten opportunities to compare the shipboard sightings with the real time detection data (one sighting was near both gliders, whereas the remaining eight sightings were near only one glider). The sightings were of right (two sightings of single animals), fin (two sightings of single animals, one sighting of a pair), humpback (three sightings of single animals), and sei whales (one sighting of a single animal). The case involving the sei whale sighting was removed from the analysis, since $N_{\text {min }}$ could not be estimated for this species (interestingly, a manual review of archived audio from 


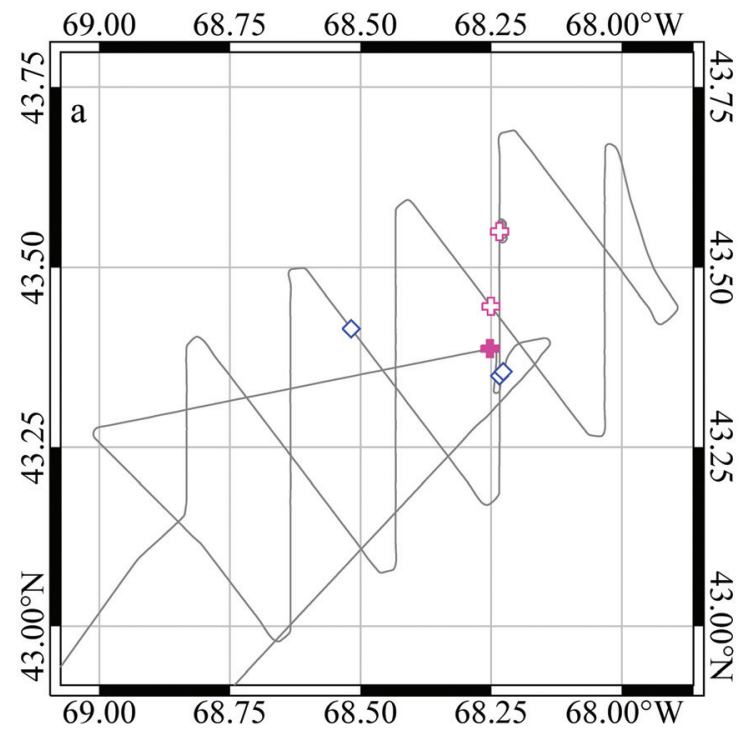

↔ Unidentified large whale
$\diamond$ Fin whale
is Humpback whale
$\bigcirc$ Right whale
$\triangle$ Sei whale

\begin{tabular}{ccccccc}
\multicolumn{8}{c}{ Scale $(\mathrm{km})$} \\
10 & 0 & 10 & 20 & 30 & 40 & 50
\end{tabular}
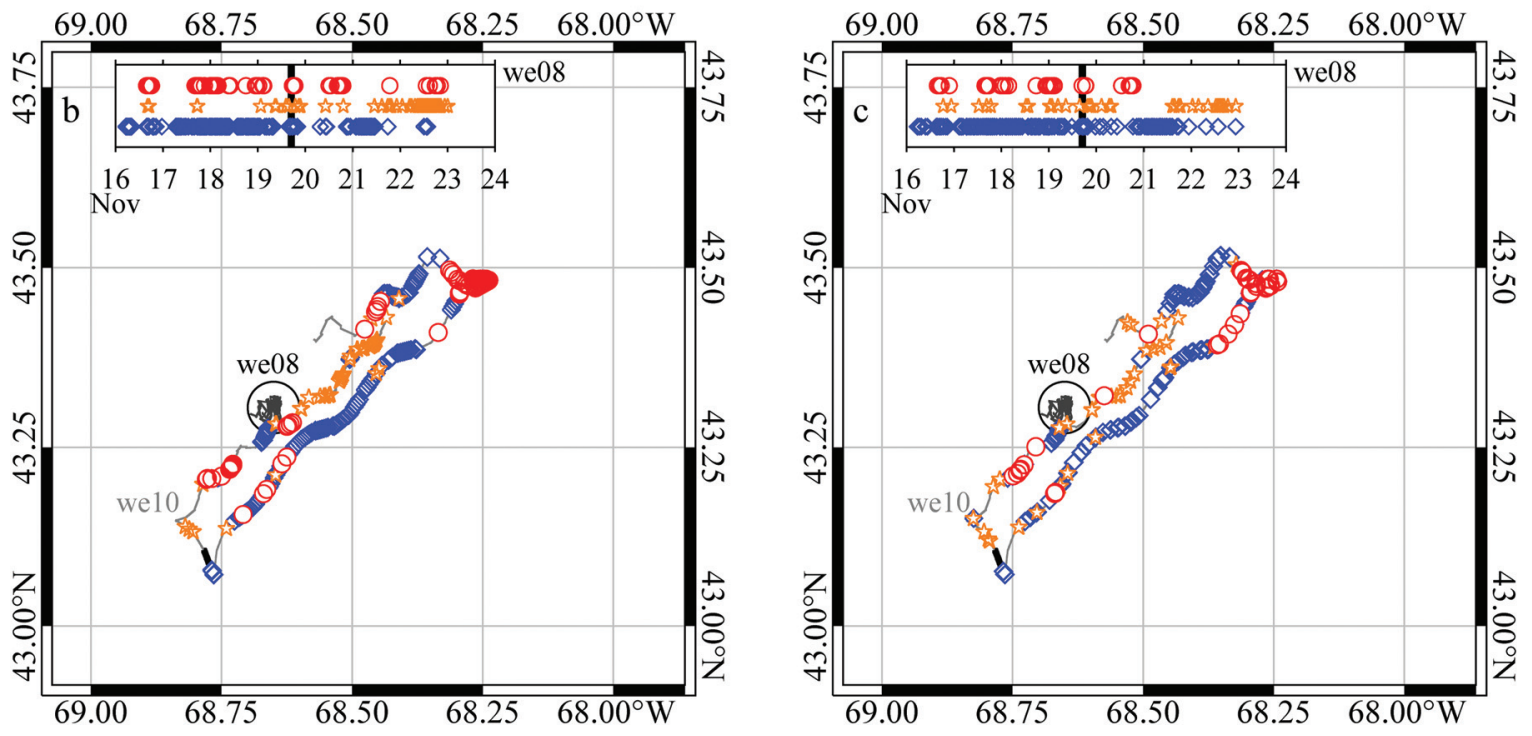

FIG. 3. (a) Track of Northeast Fisheries Science Center (NEFSC) aerial survey in the study area on 19 November 2012. Symbols indicate locations of baleen whale sightings; the filled cross indicates location of 2 unidentified large whales noted by observers as "possibly right whales." (b) Tracks of gliders we 08 (dark gray) and we10 (light gray) within \pm 3.5 days of NEFSC aerial survey. Symbols indicate glider locations or times when species occurrence was predicted, i.e., when the number of species-specific automated detections during a tally period $(N)$ was greater than or equal to $N_{\text {min }}$ (predicted sei whale occurrence is excluded since $N_{\text {min }}$ could not be estimated). Since we08 remained near a fixed location, the inset shows that glider's time series of predicted occurrences. The thick black line over the track of we10 (at the glider's most southwest location) indicates the glider's track during the NEFSC aerial survey. The vertical black band in the inset time series likewise indicates the time of the NEFSC flight. (c) Locations or times of individually detected calls that were correctly classified by the DMON/LFDCS. Only calls classified with MD $<3$, transmitted as pitch tracks in real time, and later verified by an analyst using the archived audio are shown. Since only $24 \%$ of all detected calls were transmitted as pitch tracks, not all correct individual detections are shown here.

both gliders within $\pm 12 \mathrm{~h}$ of the sei whale sighting indicated that no sei whale downsweeps were recorded during that time). For eight of the nine remaining cases (89\%), the occurrence of the sighted species was predicted by the nearby glider within $\pm 12 \mathrm{~h}$ of the sighting time (i.e., $N$ $\geq N_{\min }$ for one or more tally periods within $\pm 12 \mathrm{~h}$ of the sighting time).

\section{DISCUSSION}

Both gliders successfully provided tallies of classified baleen whale calls, a subset of detailed acoustic detection information (i.e., pitch tracks), vertical profiles of oceanographic properties (e.g., temperature, salinity), and status information continuously in real time over a period of 3 weeks while deployed in sea conditions generally inhospitable to traditional marine mammal visual surveys. In addition to the tallies, we chose to relay to shore a subset of all pitch tracks (up to $8 \mathrm{kB}$ per hour) to allow both an evaluation of the on-board classifications and the identification of call patterning (i.e., song) in real time. The tallies and pitch tracks were made available immediately on a publicly accessible website to facilitate adaptive glider mission planning as well as aerial and shipboard survey design. To our knowledge, this is the first use of real-time marine mammal acoustic detections from autonomous mobile platforms to direct survey and research activities. 

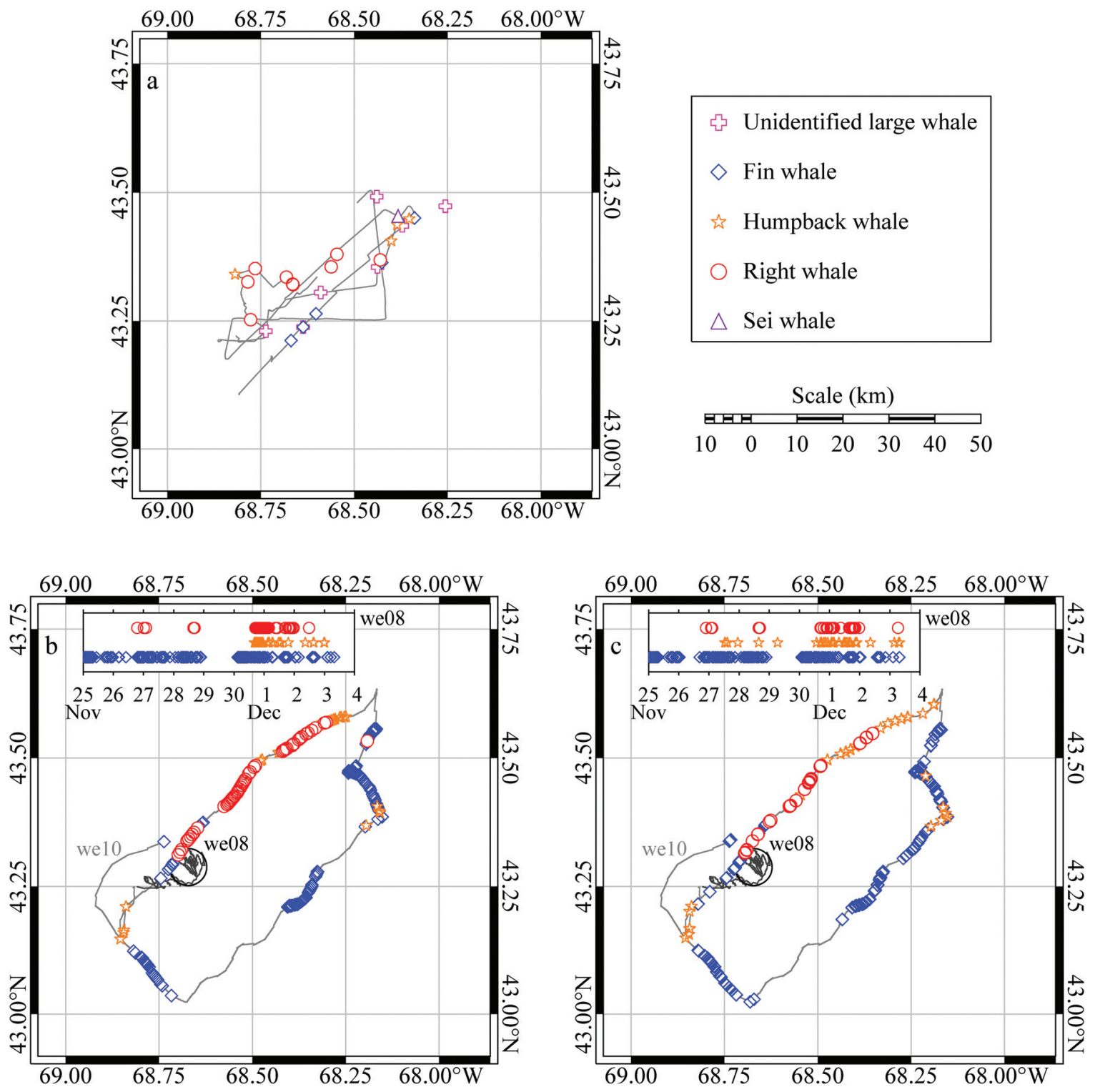

FIG. 4. (a) Track of R/V Endeavor while actively searching for baleen whales in conditions of Beaufort 5 or less. Symbols indicate locations of baleen whale sightings. (b) Tracks of gliders we08 (dark gray) and we10 (light gray) from 3.5 days prior to the Endeavor cruise to the time they were recovered. Symbols indicate glider locations or times when species occurrence was predicted during 15-min tally periods $\left(N \geq N_{\text {min }}\right.$ ). (c) Locations or times of individually detected analyst-verified calls that were correctly classified by the DMON/LFDCS and transmitted as pitch tracks in real time.

Detection accuracy was high for fin and right whales, modest for humpback whales, and undetermined for sei whales. Thresholds for detection (e.g., $\mathrm{MD}<3, N_{\min }$ ) were selected primarily to minimize false detections at the expense of missing calls so that there was high confidence in occurrence when calls were detected. We viewed false detections as more egregious than missed calls for our study, since the study species all call frequently enough to allow multiple opportunities to correctly identify a call. For example, fin whales produced $20-\mathrm{Hz}$ pulses roughly every $15 \mathrm{~s}$ when calling during our study, providing 60 opportunities in 15 min to detect the presence of the whale if calling continuously; missing 52 of those 60 calls (87\%) is acceptable for accurately predicting presence as long as the remaining 8 calls are detected correctly (recall $N_{\min }=8$ for fin whales; Table I). Moreover, if the period over which whales call is protracted relative to the tally period, the chances of missing occurrence in successive tally periods diminish. For example, if right whales are calling continuously for an hour and the probability of missing occurrence during a single 15 -min tally period is $0.50(50 \%$; Table I), then the probability of missing occurrence during two, three, and four successive tally periods is $0.25,0.125$, and 0.0625 , respectively. That is, the system would have a 1 in 16 chance of missing occurrence in all four tally periods that make up the hour in which the whales are calling.

The LFDCS requires clearly audible sounds (11 dB above background) to successfully detect calls and generate accurate pitch tracks (Baumgartner and Mussoline, 2011), and the primary reason for high missed occurrence rates (Table I) was the superior ability of an analyst to detect and recognize faint calls. During the manually analyzed 24-h period, humpback whale calls were nearly always present but were often quite faint and therefore ignored by the DMON/ 
LFDCS. While any detector is susceptible to missing faint calls, the LFDCS is particularly vulnerable, since it must both detect the presence of a sound and estimate its shape in the spectrogram with a pitch track. For humpback whales in particular, the high missed occurrence rate is also related to the selection of call types represented in the call library. Unlike fin and right whales that make comparatively stereotypical calls, humpback whales change the sounds they make from year to year (Payne et al., 1983; Payne and Payne, 1985; Noad et al., 2000), and call types constructed in previous years may not appear in the current call repertoire, resulting in high missed call rates. A future solution to this problem is to adaptively update the call library on the DMON by examining several days of transmitted pitch tracks on shore, identifying new call types, building a new call library containing those new call types, and uploading the new call library to the DMON while it is still in the field using the two-way communication capabilities of the Iridium satellite system. Each call type in the call library is represented with 116 bytes of data (a 2-byte call type identifier, a 14-byte 7-element mean attribute vector, a 98-byte 7 $\times 7$ inverted variance-covariance matrix, and a 2-byte determinant of the variance-covariance matrix), so a new expanded call library of 30 call types could be transmitted to the DMON from shore with less than $4 \mathrm{kB}$ of data.

The evaluation of the DMON/LFDCS described above was limited to the on-board classifications only; we did not attempt to quantify improvements in the real-time assessment of the acoustic detections afforded by the review of transmitted pitch tracks. Although detection accuracy for tallied humpback whale calls was modest, humpback song was unequivocal in the transmitted pitch tracks [e.g., Fig. 2(a)]. Fin whale song was likewise easily identified. The pitch tracks provided a means for an analyst to review the detection information in real time and assign a confidence level to the on-board classifications. For example, we were dubious of the real-time sei whale detections within days of the glider deployments because none of the transmitted pitch tracks classified as sei whale calls closely resembled actual sei whale low-frequency downsweeps. Just like notes on a page of sheet music, pitch tracks are a compact representation of the sound received at the DMON hydrophone. Transmission of even low-frequency audio is expensive when compared to transmitting pitch tracks: A 2-s snippet of 16-bit audio data sampled at $2000 \mathrm{~Hz}$ is 49 times more data volume than a corresponding 2 -s pitch track (8000 vs 162 bytes; note, however, that most pitch tracks were shorter in duration and were transmitted in only 68 bytes on average). Because of the relatively low data volume, we could send to shore enough pitch tracks to provide an analyst with the patterning and context of calls in a way that would be impossible to achieve with audio snippets.

When whales were sighted during the aerial or shipboard surveys and a glider was nearby (within $20 \mathrm{~km}$ ), those sightings were nearly always accompanied by a predicted occurrence of the same species by the glider (within $\pm 12 \mathrm{~h}$ ). The sightings of only fin whales during the aerial survey were particularly interesting, since the gliders' acoustic detections suggested that right, humpback, and fin whales were present in the study area during the week of the flight and in the case of glider we 08 , during the day of the flight [Fig. 3(b)]. Sightings from both the aerial and shipboard surveys never consisted of more than two whales, and most sightings were of single animals. Clark et al. (2010) suggested that aerial surveys are less effective than acoustic monitoring, particularly when whale abundance is low, because of the aircraft's fast speed and the sometimes-long submergences by the whales. Our study area was characterized by low sighting rates of singles and pairs of animals, so it is perhaps not surprising that the aerial survey did not detect right and humpback whales during the flight despite the acoustic detections reported by the gliders.

From a scientific standpoint, the gliders accomplished their mission of characterizing the distribution of whales accurately enough to aid in our finding whales quickly upon arrival on location aboard the R/V Endeavor. On the first survey day when sea conditions calmed to Beaufort 6 or less (30 November), we encountered a right whale within $3 \mathrm{~h}$ of beginning our search just to the north of glider we08. From a management perspective, our right whale sightings were reported to NOAA Fisheries, and NOAA, in turn, implemented a "Dynamic Management Area" (DMA) in the study region and requested that mariners voluntarily avoid the area or transit through it at $10 \mathrm{kn}$ or less. Right whales are at serious risk from ship strikes (Kraus et al., 2005; Silber et al., 2012), and the action by NOAA was meant to protect the whales we encountered from harm. Our study demonstrated that autonomous platforms can conduct real-time passive acoustic reconnaissance to improve the efficiency of aerial or shipboard visual surveys for either scientific or management applications.

The DMON/LFDCS is "platform agnostic," meaning that it "knows" very little about the platform upon which it is deployed. Using different hydrophone configurations, we have integrated the DMON/LFDCS into APEX profiling floats (Teledyne Webb Research) and moored buoys with very little modification to the LFDCS software. Using the desktop computer version of the LFDCS (Baumgartner and Mussoline, 2011), we have built call libraries for tonal calls produced by several additional marine mammals, including bowhead (Balaena mysticetus) and blue (Balaenoptera musculus) whales and ribbon (Histriophoca fasciata) and bearded (Erignathus barbatus) seals, and these libraries can be used without modification by the DMON/LFDCS. The pitch tracking algorithm is also easily adapted to detecting the whistles of odontocetes, as it is a form of call contouring originally developed for characterizing dolphin whistles (e.g., Buck and Tyack, 1993; Suzuki and Buck, 2000; Oswald et al., 2007). The DMON can be configured with low- $(8-7500 \mathrm{~Hz})$, mid$(100-50000 \mathrm{~Hz})$, and high-frequency $(1-160 \mathrm{kHz})$ hydrophones, and early tests indicate that real-time detection of odontocete whistles with the DMON mid-frequency hydrophone and the LFDCS algorithm is feasible. Ultimately, we wish to simultaneously detect a wide range of species that produce sound in several frequency bands using a single DMON, and to deploy this capability on a variety of autonomous platforms to meet the diverse real-time monitoring needs of both scientists and managers. 


\section{ACKNOWLEDGMENTS}

Ben Hodges and Nick Woods expertly deployed the gliders. At sea assistance was provided by the captains and crew of the R/V Gulf Challenger and R/V Endeavor, as well as the following Endeavor cruise participants: Marianna Hagbloom, Nadine Lysiak, Tracy Montgomery, Desray Reeb, Morgan Rubanow, and Chris Tremblay. Corey Accardo, Pete Duley, and Jen Gatzke conducted the NOAA aerial survey. The Office of Naval Research funded this work, with additional support provided by the NOAA Fisheries Advanced Sampling Technologies Working Group via the Cooperative Institute for the North Atlantic Region.

Baumgartner, M. F., and Fratantoni, D. M. (2008). "Diel periodicity in both sei whale vocalization rates and the vertical migration of their copepod prey observed from ocean gliders," Limnol. Oceanogr. 53, 2197-2209.

Baumgartner, M. F., and Mussoline, S. E. (2011). "A generalized baleen whale call detection and classification system," J. Acoust. Soc. Am. 129, 2889-2902.

Baumgartner, M. F., Van Parijs, S. M., Wenzel, F. W., Tremblay, C. J., Esch, H. C., and Warde, A. M. (2008). "Low frequency vocalizations attributed to sei whales (Balaenoptera borealis)," J. Acoust. Soc. Am. 124, 1339-1349.

Buck, J. R., and Tyack, P. L. (1993). “A quantitative measure of similarity for Tursiops truncatus signature whistles," J. Acoust. Soc. Am. 94, 2497-2506.

Clark, C. W. (1982). "The acoustic repertoire of the southern right whale, a quantitative analysis," Anim. Behav. 30, 1060-1071.

Clark, C. W. (1983). "Acoustic communication and behavior of the southern right whale," in Behavior and Communication of Whales, edited by R. S. Payne (Westview Press, Boulder, CO), pp. 163-198.

Clark, C. W., Borsani, J. F., and Notarbartolo-Di-Sciara, G. (2002). "Vocal activity of fin whales, Balaenoptera physalus, in the Ligurian Sea," Mar. Mammal Sci. 18, 286-295.

Clark, C. W., Brown, M. W., and Corkeron, P. (2010). "Visual and acoustic surveys for North Atlantic right whales, Eubalaena glacialis, in Cape Cod Bay, Massachusetts, 2001-2005: Management implications," Mar. Mammal Sci. 26, 837-854.

Clark, C. W., Calupca, T., Gillespie, D., Von der Heydt, K., and Kemp, J. (2005). "A near-real-time acoustic detection and reporting system for endangered species in critical habitats," J. Acoust. Soc. Am. 117, 2525.

Cole, T. V. N., Gerrior, P., and Merrick, R. L. (2007). "Methodologies of the NOAA National Marine Fisheries Service aerial survey program for right whales (Eubalaena glacialis) in the Northeast U.S., 1998-2006," U.S. Department of Commerce, Northeast Fisheries Science Center Reference Document 07-02; 11 p. Available online at http://www.nefsc.noaa.gov/publications/crd/crd0702/ (Last viewed 4 April 2013)

Forney, K. A., Ferguson, M. C., Becker, E. A., Fiedler, P. C., Redfern, J. V., Barlow, J., Vilchis, I. L., and Balance, L. T. (2012). "Habitat-based spatial models of cetacean density in the eastern Pacific Ocean," Endanger. Species Res. 16, 113-133.

Gillespie, D., Gordon, J., Mchugh, R., Mclaren, D., Mellinger, D., Redmond, P., Thode, A., Trinder, P., and Deng, X. Y. (2008). "PAMGUARD: Semiautomated, open source software for real-time acoustic detection and localisation of cetaceans," Proc. Inst. Acoust. 30(5), 9.

Johnson, M., Partan, J., and Hurst, T. (2013). "Low complexity lossless compression of underwater sound recordings," J. Acoust. Soc. Am. 133, 1387-1398.

Klinck, H., Mellinger, D. K., Klinck, K., Bogue, N. M., Luby, J. C., Jump, W. A., Shilling, G. B., Litchendorf, T., Wood, A. S., Schorr, G. S., and Baird, R. W. (2012). "Near-real-time acoustic monitoring of beaked whales and other cetaceans using a Seaglider ${ }^{\mathrm{TM}}$," PLoS ONE 7, e36128. doi:10.1371/journal.pone.0036128.
Kraus, S. D., Brown, M. W., Caswell, H., Clark, C. W., Fujiwara, M., Hamilton, P. K., Kenney, R. D., Knowlton, A. R., Landry, S., Mayo, C. A., McLellan, W. A., Moore, M. J., Nowacek, D. P., Pabst, D. A., Read, A. J., and Rolland, R. M. (2005). "North Atlantic right whales in crisis," Science 309, 561-562.

Kumar, A., Nissen, J., Bell, J., and Shoemaker, M. (2012). "Using passive acoustics to monitor the presence of marine mammals during naval exercises," Adv. Exp. Med. Biol. 730, 641-643.

MacLeod, C. D., Perrin, W. F., Pitman, R., Barlow, J., Balance, L., D’Amico, A., Gerrodette, T., Joyce, G., Mullin, K. D., Palka, D. L., and Waring, G. T. (2006). "Known and inferred distributions of beaked whale species (Cetacea: Ziphiidae)," J. Cetacean Res. Manage. 7, 271-286.

Matsumoto, H., Jones, C., Klinck, H., Mellinger, D. K., Dziak, R. P., and Meinig, C. (2013). "Tracking beaked whales with a passive acoustic profiler float," J. Acoust. Soc. Am. 133, 731-740.

Mellinger, D. K., Stafford, K. M., Moore, S. E., Dziak, R. P., and Matsumoto, H. (2007). "An overview of fixed passive acoustic observation methods for cetaceans," Oceanography 20, 36-45.

Moore, S. E., Howe, B. M., Stafford, K. M., and Boyd, M. L. (2007). "Including whale call detection in standard ocean measurements: Application of acoustic Seagliders," Mar. Technol. Soc. J. 41, 53-57.

Morano, J. L., Salisbury, D. P., Rice, A. N., Conklin, K. L., Falk, K. L., and Clark, C. W. (2012). "Seasonal and geographical patterns of fin whale song in the western North Atlantic Ocean," J. Acoust. Soc. Am. 132, 1207-1212.

Noad, M. J., Cato, D. H., Bryden, M. M., Jenner, M. N., and Jenner, K. C. S. (2000). "Cultural revolution in whale songs," Nature 408, 537-537.

Oswald, J. N., Rankin, S., Barlow, J., and Lammers, M. O. (2007). "A tool for real-time acoustic species identification of delphinid whistles," J. Acoust. Soc. Am. 122, 587-595.

Payne, K., and Payne, R. (1985). "Large scale changes over 19 years in songs of humpback whales in Bermuda," Z. Tierpsychol. 68, 89-114.

Payne, K., Tyack. P., and Payne, R. (1983) "Progressive changes in the song of humpback whales (Megaptera novaeangliae): A detailed analysis of two seasons in Hawaii," in Communication and Behavior of Whales, edited by R. Payne (Westview Press, Boulder, CO), pp. 9-57.

Rankin, S., and Barlow, J. (2007). "Vocalizations of the sei whale Balaenoptera borealis off the Hawaiian Islands," Bioacoustics 16, 137-145.

Schevill, W. E., Backus, R. H., and Hersey, J. B. (1962). "Sound production by marine animals," in Bioacoustics, edited by M. N. Hill (Wiley, New York), pp. 540-566.

Silber, G. K., Vanderlaan, A. S. M., Tejedor Arceredillo, A., Johnson, L., Taggart, C. T., Brown, M. W., Bettridge, S., and Sagarminaga, R. (2012). "The role of the International Maritime Organization in reducing vessel threat to whales: Process, options, action and effectiveness," Mar. Policy 36, 1221-1233.

Simard, Y., Bahoura, M., Park, C. W., Rouat, J., Sirois, M., Mouy, X., Seebaruth, D., Roy, N., and Lepage, R. (2006). "Development and experimentation of a satellite buoy network for real-time acoustic localization of whales in the St. Lawrence," Proceedings of Oceans 2006 MTS/IEEE, Boston Massachusetts, 18-21 September 2006. 6 pp.

Spaulding, E., Robbins, M., Calupca, T., Clark, C., Tremblay, C., Waack, A., Warde, A., Kemp, J., and Newhall, K. (2009). "An autonomous, nearreal-time buoy system for automatic detection of North Atlantic right whale calls," J. Acoust. Soc. Am. 125, 2615.

Suzuki, R., and Buck, J. R. (2000). "Extraction and tracking of bottlenose dolphin whistle contours,” J. Acoust. Soc. Am. 108, 2635-2636.

Van Parijs, S. M., Clark, C. W., Sousa-Lima, R. S., Parks, S. E., Rankin, S., Risch, D., and Van Opzeeland, I. C. (2009). "Management and research applications of real-time and archival passive acoustic sensors over varying temporal and spatial scales," Mar. Ecol. Prog. Ser. 395, 21-36.

Watkins, W. A., Tyack, P., Moore, K. E., and Bird, J. E. (1987). "The 20-Hz signals of finback whales (Balaenoptera physalus)," J. Acoust. Soc. Am. 82, 1901-1912. 